University of Nebraska - Lincoln

DigitalCommons@University of Nebraska - Lincoln

9-17-2004

\title{
Chemical/Mechanical Analyses of Anhydride-Cured Thermosetting Epoxys: DGEBA/NMA/BDMA
}

Wei Chian

Department of Chemistry and Chemical Engineering, South Dakota School of Mines, Rapid City, South Dakota 57701

Delmar C. Timm

University of Nebraska-Lincoln, dtimm1@unl.edu

Follow this and additional works at: https://digitalcommons.unl.edu/chemengmolecular

Part of the Chemical Engineering Commons

Chian, Wei and Timm, Delmar C., "Chemical/Mechanical Analyses of Anhydride-Cured Thermosetting Epoxys: DGEBA/NMA/BDMA" (2004). Papers in Molecular Chemistry. 2.

https://digitalcommons.unl.edu/chemengmolecular/2

This Article is brought to you for free and open access by the Chemical and Biomolecular Engineering Research and Publications at DigitalCommons@University of Nebraska - Lincoln. It has been accepted for inclusion in Papers in Molecular Chemistry by an authorized administrator of DigitalCommons@University of Nebraska - Lincoln. 


\title{
Chemical/Mechanical Analyses of Anhydride-Cured Thermosetting Epoxys: DGEBA/NMA/BDMA
}

\author{
Wei Chian $\uparrow$ and Delmar C. Timm*
}

$\dagger$ Department of Chemistry and Chemical Engineering, South Dakota School of Mines, Rapid City, South Dakota 57701 ,

* Department of Chemical Engineering, University of Nebraska-Lincoln, Lincoln, Nebraska 68588

Macromolecules; (Article); 2004; 37(21); 8098-8109.

Received April 12, 2004; Revised Manuscript Received July 14, 2004

Published on web : 09/17/2004.

Copyright @ 2004 American Chemical Society.

The American Chemical Society allows the posting of only the title, abstract, tables, and figures from articles appearing in the Macromolecules.

This article is published online at http://pubs.acs.org/journals

DOI: $\underline{10.1021 / \mathrm{ma} 0492925}$ 


\section{ABSTRACT:}

The chemical state of cure in a thermosetting resin was used to predict the resin's equilibrium modulus. High performance liquid chromatography analyses of the sol fraction yielded molar dynamics for monomeric, oligomeric, and polymeric molecules. Their population density distributions were compared with theoretical predictions based on a chain-growth polymerization mechanism. The resulting chemical estimates of the state of cure were integrated into calculations yielding concentrations of network structures within the gel that contribute to the density of elastically active strands and junctions. The theory of rubber elasticity was then used to predict the equilibrium modulus. Measurements incorporated dynamic mechanical analysis. A comprehensive understanding of the polymerization mechanism and cure history are required for accurate simulations of contributions from branch nodes and chain links. Deterministic models based solely on chemical reaction analysis were used to estimate chain connectivity with the gel. Results were interpreted using stochastic-based reasoning.

\subsection{1/ma0492925 @ 2004 American Chemical Society Published on Web 09/17/2004}

(C) 2004 American Chemical Society

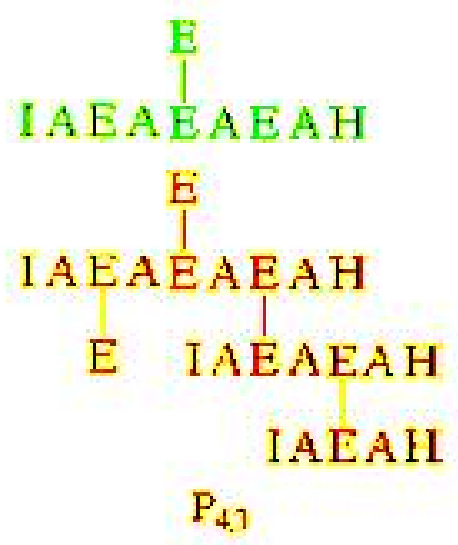

Fixure 1. Representat me mederite $P_{\text {.. }}$ for the tesin [DCEBA NRLABDMAA. 


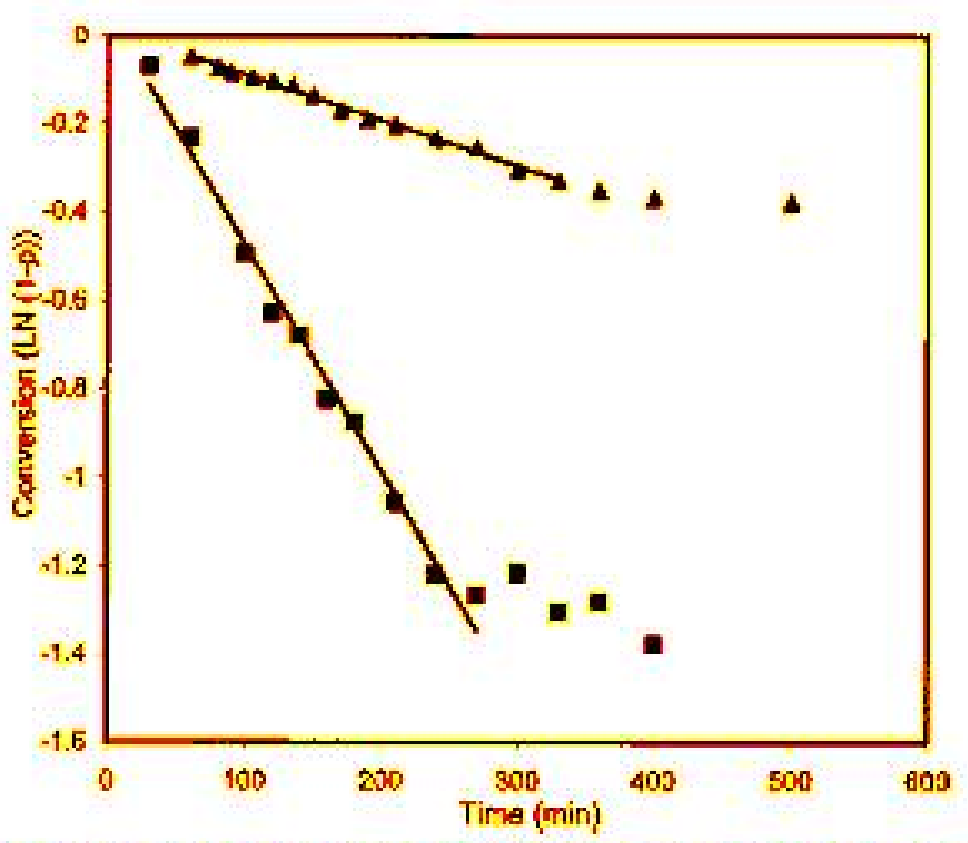

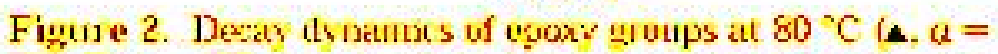
200. $a-20$

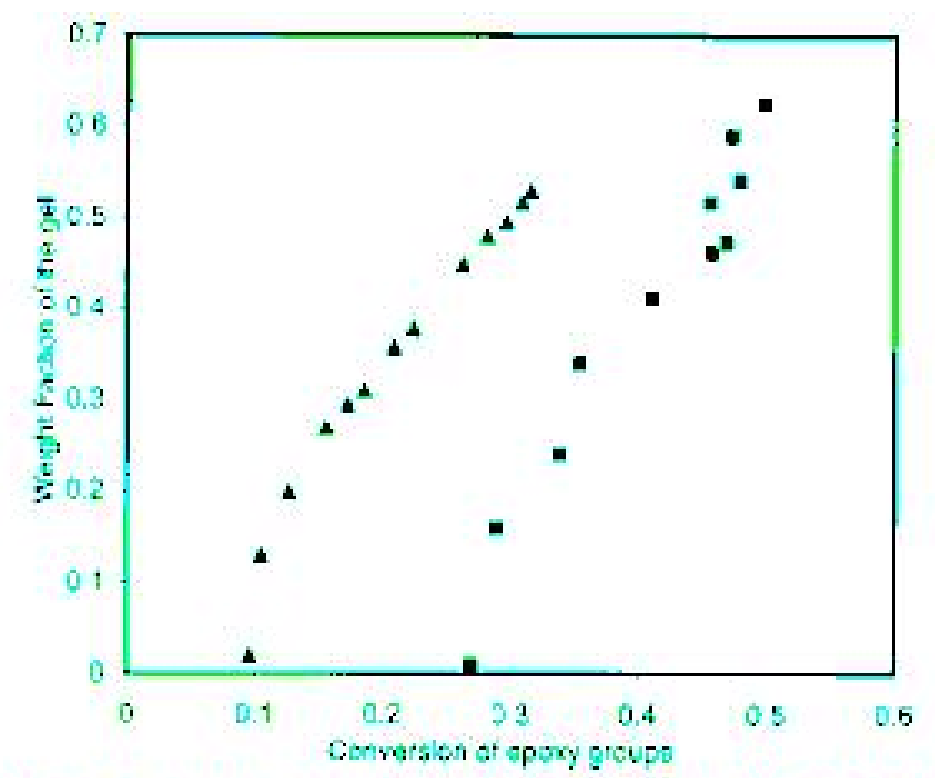

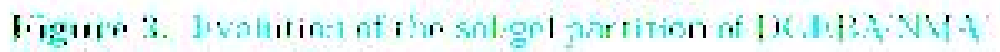

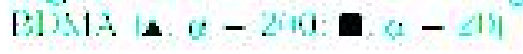

(C) 2004 American Chemical Society 
(C) 2004 American Chemical Society

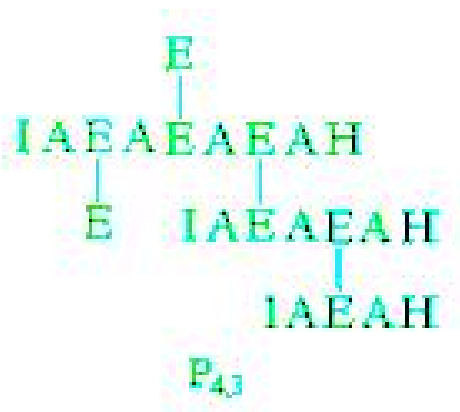

Figure 1. Represerutaclve rnolecule $\mathrm{P}_{i j}$ for the resin DGEBAj NWABDMA.

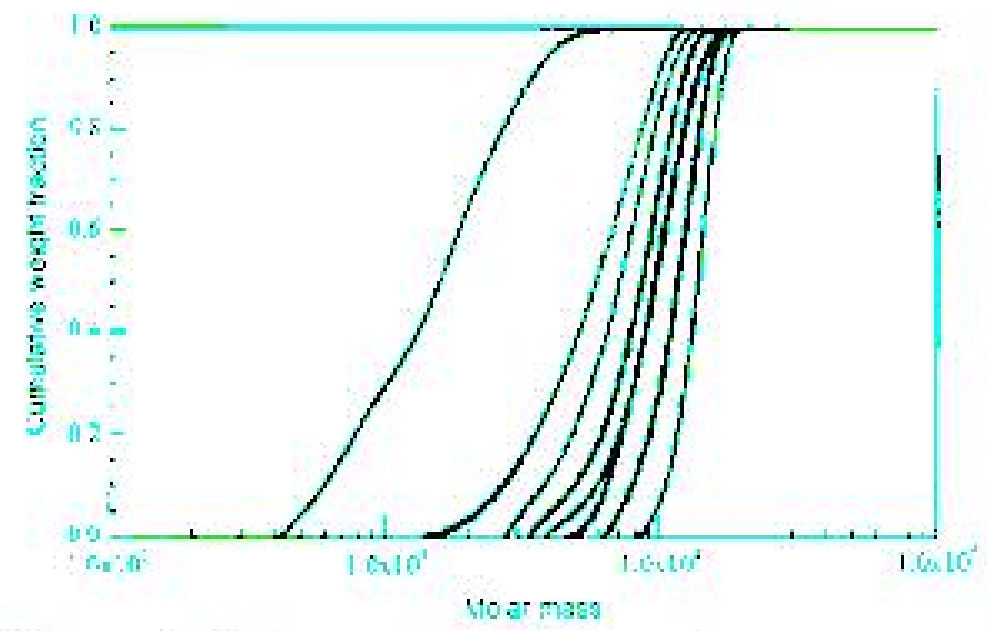

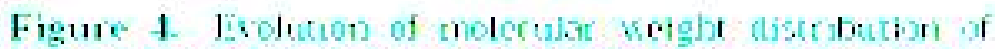

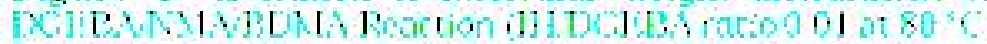

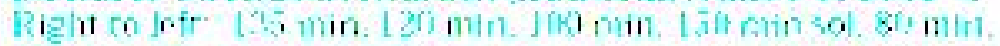

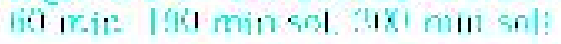

(C) 2004 American Chemical Society 

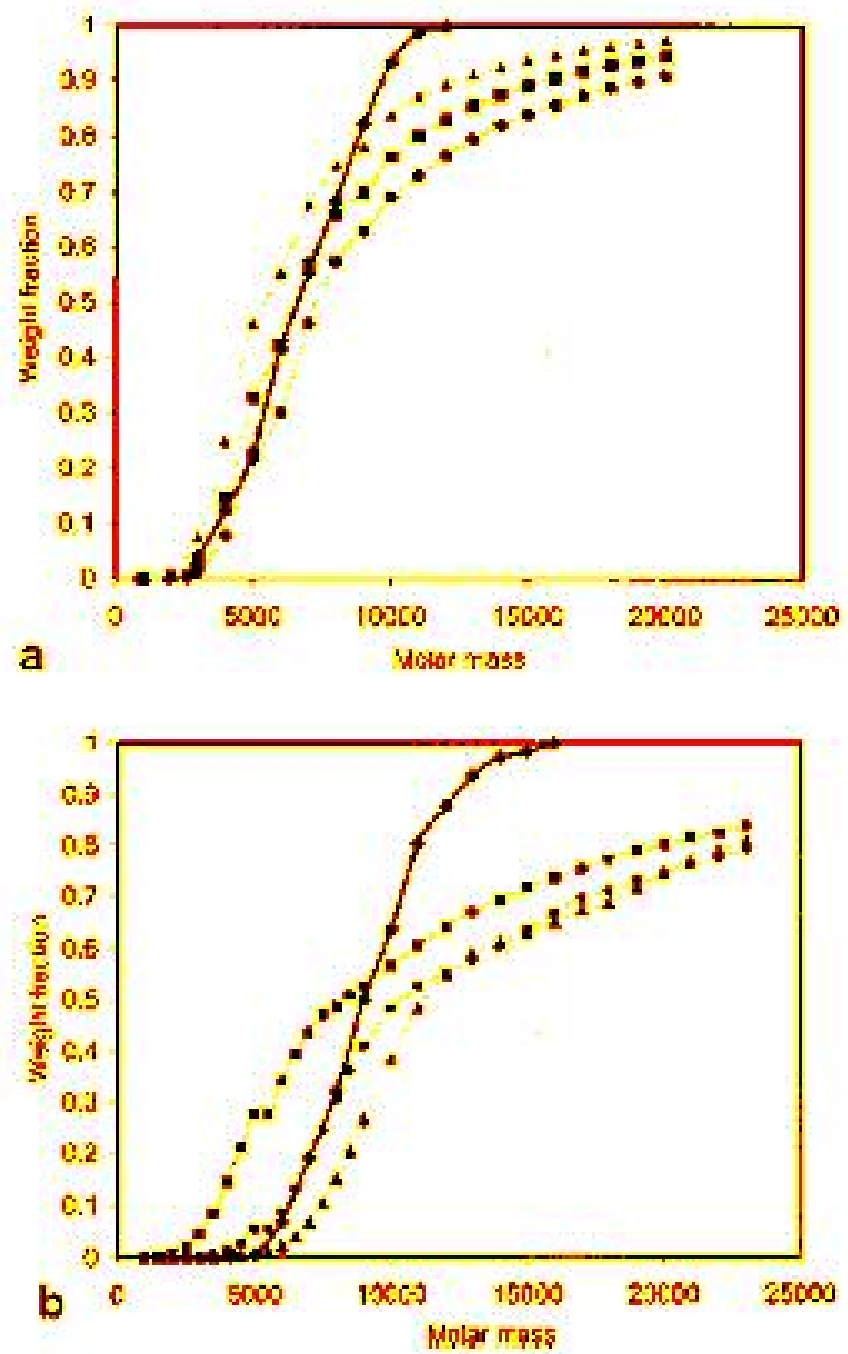

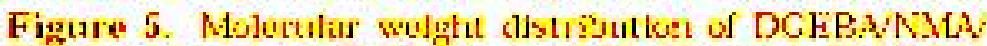

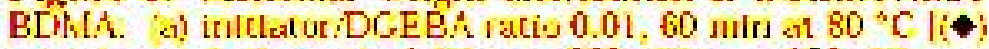

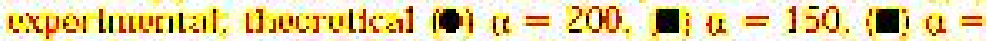

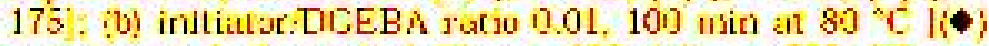

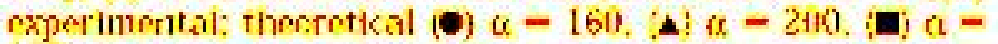
120

(C) 2004 American Chemical Society 


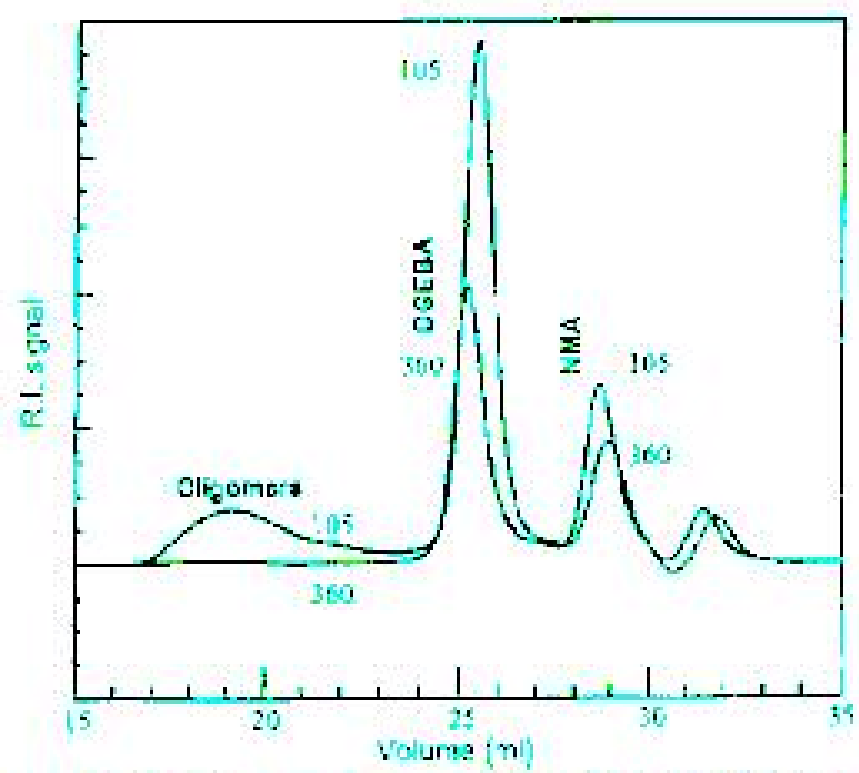

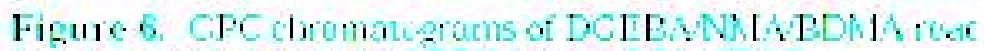

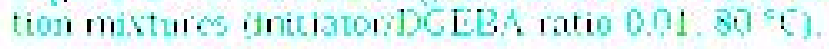

\section{C) 2004 American Chemical Society}




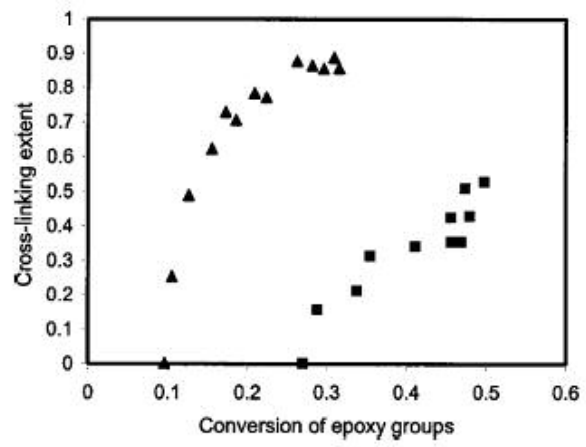

Figure 7. Cross-linking dynamics at $80^{\circ} \mathrm{C}(\boldsymbol{\Lambda}, \alpha=200 ; \mathbf{a}, \alpha$ $=20$ )

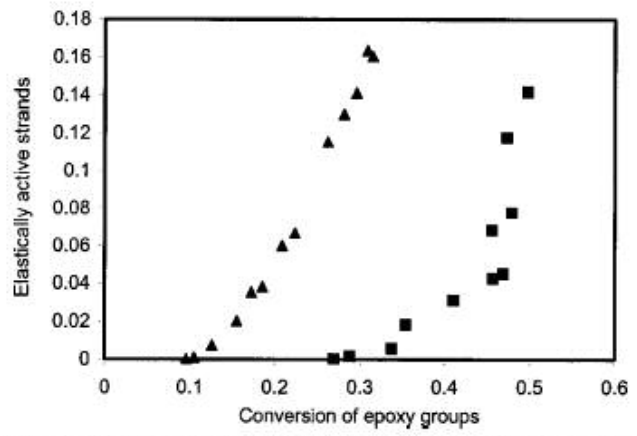

Figure 8. Theoretical growth of elastically active strands $(\boldsymbol{\Lambda}$, $\alpha=200 ; \mathbf{a}, \alpha=20$ ).

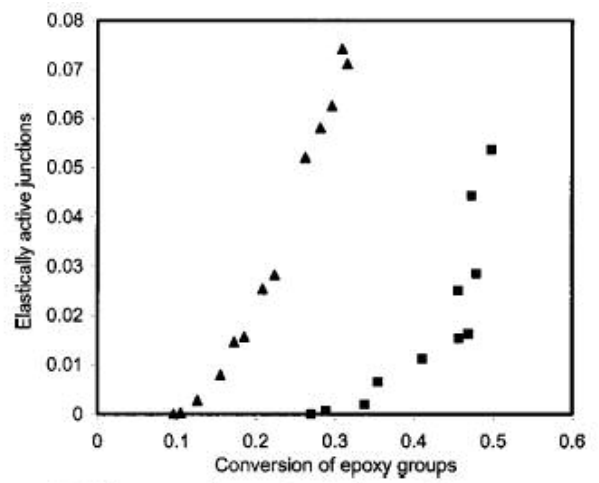

Figure 9. Theoretical growth of elastically active junctions $(\boldsymbol{\Lambda}, \alpha=200 ; \boldsymbol{\square}, \alpha=20$ ).

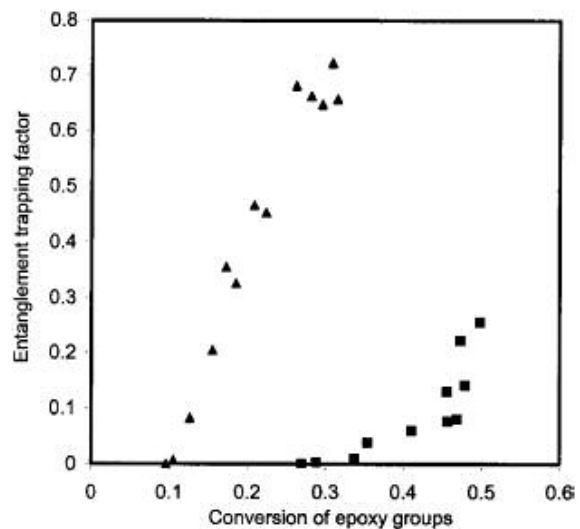

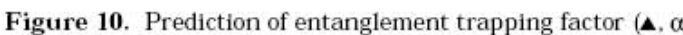
$=200 ; \mathbf{\square}, \alpha=20$ ).

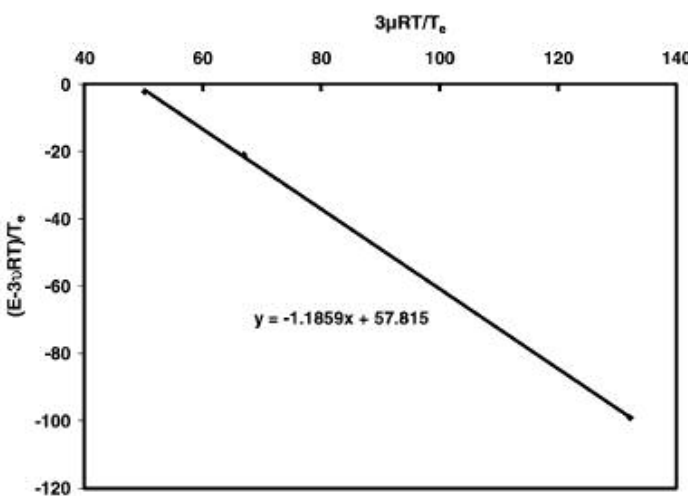

Figure 11. Experimental-theoretical comparison of rubber equilibrium modulus (assuming an affine network).

\section{(C) 2004 American Chemical Society}

